\begin{tabular}{|c|l|}
\hline Title & A tomic imaging of an InSe single crystal surface with atomic force microscope \\
\hline Author(s) & U osaki, Kohei; Koinuma, Michio \\
\hline Citation & $\begin{array}{l}\text { Journal of A pplied Physics, } 74(3), 1675-1678 \\
\text { https://doi.org/10.1063/1.354820 }\end{array}$ \\
\hline Issue Date & 1993-08-01 \\
\hline Doc URL & http://hdl.handle.net/2115/20579 \\
\hline Rights & Copyright $\odot$ 1993 A merican Institute of Physics \\
\hline Type & article \\
\hline File Information & JAP74. 3.pdf \\
\hline
\end{tabular}

Instructions for use 


\title{
Atomic imaging of an InSe single-crystal surface with atomic force microscope
}

\author{
Kohei Uosaki and Michio Koinuma \\ Department of Chemistry, Faculty of Science, Hokkaido University, Sapporo 060, Japan
}

(Received 10 September 1992; accepted for publication 20 April 1993)

\begin{abstract}
The atomic force microscope was employed to observed in air the surface atomic structure of InSe, one of III-VI compound semiconductors with layered structures. Atomic arrangements were observed in both $n$-type and $p$-type materials. The observed structures are in good agreement with those expected from bulk crystal structures. The atomic images became less clear by repeating the imaging process. Wide area imaging after the imaging of small area clearly showed that a mound was created at the spot previously imaged.
\end{abstract}

\section{INTRODUCTION}

InSe is one of the III-VI compound semiconductors with a layered structure. ${ }^{1}$ It has interesting properties such as strong conducting anisotropy and insensitivity of cleaved surfaces to the adsorption of foreign atoms and molecules. ${ }^{2,3}$ These characteristics are common to all layered compounds. Furthermore, InSe has a high photosensitivity with an optimum energy gap for solar energy conversion $(1.3 \mathrm{eV}){ }^{4}$ Thus, not only optical ${ }^{5,6}$ and electronic ${ }^{6,7}$ properties but also photovoltaic ${ }^{2,8}$ and photoelectrochemical ${ }^{9-11}$ characteristics of InSe have been studied, although the latter properties have not been investigated as extensively as transition metal dichalcogenides, which also have a layered structure.

It is obvious that the chemical reactivity of InSe should be strongly affected depending upon whether the cleaved van der Waals face or the one perpendicular to the cleaved face is exposed. Naturally, perfection of the surface structure is also important to determine the chemical reactivity of the InSe surface. Since the step is expected to act as an efficient recombination center for electron-hole pairs generated by illumination, the surface perfection is one of the most important parameters to determine the photovoltaic and photoelectrochemical characteristics of InSe. We have already demonstrated that the photocurrent is small at steps in the photoelectrochemical arrangement by using laser spot scanning microscope. ${ }^{12,13}$ We also showed that the surface treatment of an InSe surface with $\mathrm{Pt}$ increases the rate for the photoelectrochemical hydrogen evolution reaction. ${ }^{12,14}$

Thus, it is important to obtain information on the surface structure of an InSe crystal in air and in solution. The scanning tunneling microscope (STM) and the atomic force microscope (AFM) are becoming popular tools to determine surface structures with atomic resolution not only in a vacuum but also in air and even in solution. Although transition metal dichalcogenides have been considered to be ideal materials for STM and AFM investigation, and many papers have been published, ${ }^{15-17}$ no reports on InSe are available.

In this paper, we report on the surface structure of InSe determined by AFM in air with atomic resolution and discuss the effect of imaging on the observed surface structure.

\section{EXPERIMENTAL SECTION}

$n$-type (undoped) and $p$-type (Zn-doped) InSe single crystals grown by the Bridgman-Stockbarger method from the $\mathrm{In}_{1.12} \mathrm{Se}_{0.88}$ liquid phase were donated by Chevy et al. ${ }^{18}$ Before each experiment, a clean surface was obtained by removing some layers by using adhesive tape.

A NanoScope II with an AFM unit (Digital Instruments, CA) was used. All the measurements were conducted in air in a constant force mode by using an $A$-head (scan size $=0.7 \mu \mathrm{m}$ ). Microfabricated silicon nitride cantilevers $100 \mu \mathrm{m}$ in length with a spring constant of 0.58 $\mathrm{N} / \mathrm{m}$ were used. AFM tips integrated with the cantilevers were also made of silicon nitride and were $4 \mu \mathrm{m}$ long with nominal radii of less than $40 \mathrm{~nm}$. The typical force during the measurements was $\sim 10 \mathrm{nN}$. Calibrations of the piezo scanner for the $x$ and $y$ plane were carried out by imaging highly oriented pyrolytic graphite (HOPG) and mica. No attempt was made to calibrate the scanner in the $z$ direction and the calibration value provided by the manufacturer was used.

\section{RESULTS AND DISCUSSION}

Figure 1(a) shows a typical AFM image $(3.01 \mathrm{~nm}$ $\times 3.01 \mathrm{~nm}$ ) of a $p$-InSe surface obtained with 16 lines $/ \mathrm{s}$ $\times 200$ lines/image. The hexagonal arrangement of the topmost atoms can be clearly seen with a distance between the closest neighbor atoms of $0.41 \pm 0.01 \mathrm{~nm}$. Furthermore, atoms which situate $0.2 \mathrm{~nm}$ below the first layer were also imaged as shown in the sectional view [Fig. 1(b)]. No effect of $\mathrm{Zn}$ doping was observed. In some cases a much greater or smaller atomic distance was observed, but we found these results were obtained when the surface of the sample was not flat.

At least two structures have been proposed for InSe based on XRD analyses, i.e., a hexagonal structure with unit cell of $a=0.400$ and $c=1.664 \mathrm{~nm}$ (Refs. 19, 20) and a rhombohedral structure with $a=0.400$ and $c=2.485$ $\mathrm{nm} .{ }^{21}$ In both cases each layer consists of four-layered slabs of Se-In-In-Se. The difference between the two suggested structures is the rcsult of the different stacking sequence of 


\section{(a)}

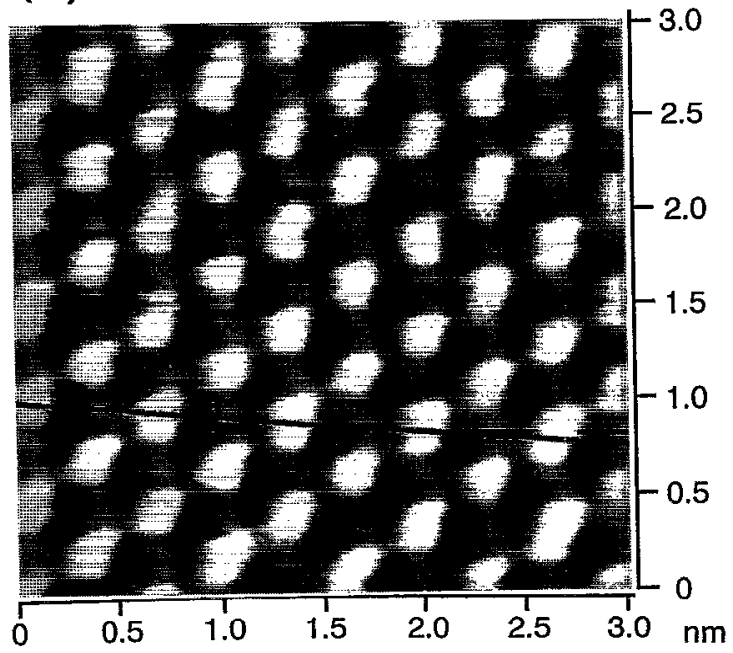

(b)

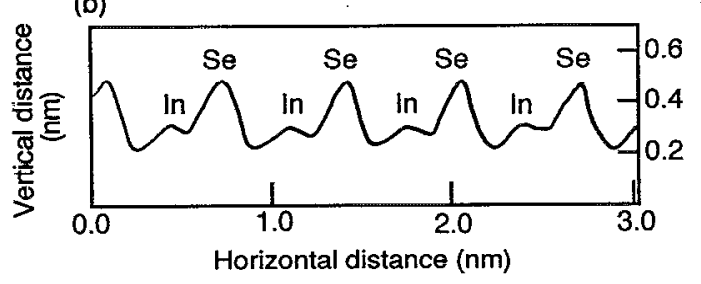

FIG. 1. (a) AFM top view image ( $3 \mathrm{~nm} \times 3 \mathrm{~nm}$ ) of van ver Waals face of $p$-InSe. (b) Sectional view of the surface across the black line shown in the AFM image.

the slabs. The latter structure, which is known to be the dominant structure of the InSe crystal grown by the Bridgman method, is presented in Fig. 2. In this case, the unit cell extends over three layers. On the other hand, a two slab repetition results in the hexagonal structure. As far as the AFM image of the van der Waals face is concerned, no difference was expected between the two structures. The topmost and the second atom layers should be Se and In, respectively. The atomic distance of the neighboring atoms of the topmost layer determined by AFM measurement was in good agreement with the value $(0.4 \mathrm{~nm})$ estimated from the crystal structures. The hexagonal arrangement of (a)

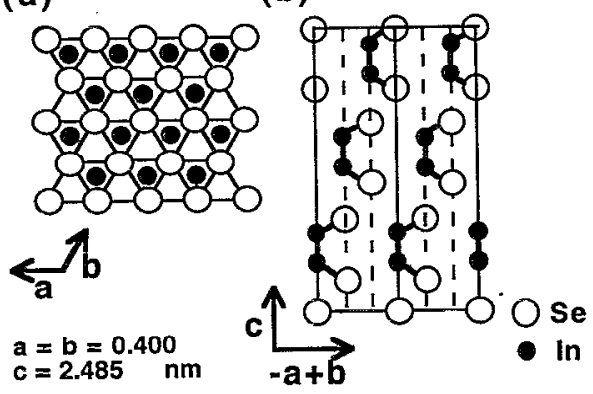

FIG. 2. (a) The atomic arrangement of the topmost and second of van der Waals face of InSe. (b) The stacking sequence of InSe in rhombohedral structure.

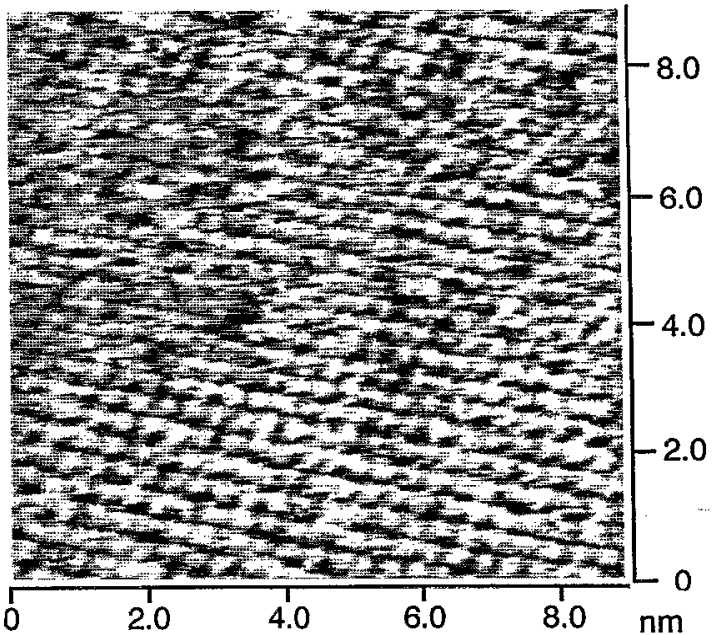

FIG. 3. AFM image ( $9.0 \mathrm{~nm} \times 9.0 \mathrm{~nm})$ of $n$-InSe.

the topmost atoms was also observed as expected from the crystal structures. Indium atoms in the second atom layer were also in a hexagonal arrangement with $\sim 0.4 \mathrm{~nm}$ atomic distance as expected. However, the relative position of In to Se was different from the one expected from XRD analyses. The expected vertical distance between a Se atom and the nearest In atom was $0.126 \mathrm{~nm}$, but the observed distance was $\sim 0.19 \mathrm{~nm}$ as shown in Fig. 1(b). Horizontal distances between an In atom and the nearest and second nearest Se atoms were expected to be 0.23 and $0.46 \mathrm{~nm}$, respectively, but the observed values were 0.32 and 0.36 $\mathrm{nm}$, respectively [see Fig. 2(b)]. These discrepancies should have been partly due to the irregular shape of the tip that is suggested by the unsymmetrical shape of the atoms which is observed in the sectional view [Fig. 1(b)]. Furthermore, since the measurements were conducted in air, the surface was covered with some contaminants and, therefore, the absolute value in the vertical direction was hard to determine. One must also note that no calibration for the $z$ direction of the scanner was carried out. Essentially the same images were obtained for an $n$-type sample.

An almost defect-free atomic arrangement was obtained even at a wide scan $(9.0 \mathrm{~nm} \times 9.0 \mathrm{~nm})$ as shown in Fig. 3. There are, however, some portions (left-hand side) where the atomic image is less clear. There are several reasons for this. One is an intrinsic defect and the other is surface contamination. The third possibility is a defect created by the AFM imaging itself. Actually the atomic images became less clear by repeating the imaging for $2 \mathrm{~min}$ and the atoms were not resolved after 3 min of imaging. However, the atomic image was obtained if the imaging spot was changed, suggesting that the failure of atomic imaging is not due to the surface contamination but due to the effect of AFM imaging itself.

Figure 4 shows a wide scan AFM imagc (500 nm $\times 500 \mathrm{~nm}$ ) of $n$-InSe sequentially obtained every $40 \mathrm{~s}$. It took $10 \mathrm{~s}$ to obtain one image (19.5 lines/s $\times 200$ lines/ image). Figure $4(a)$ is the first image, showing that the surface is atomically flat for a very wide area. The histo- 
(a)

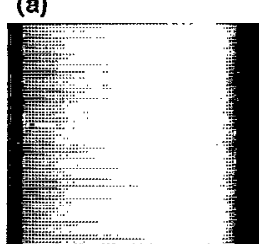

(d)

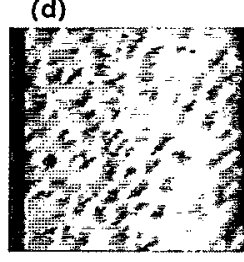

(b)

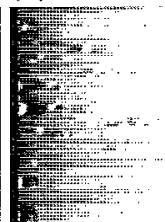

(e)

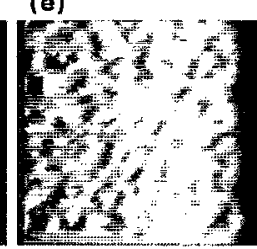

(c)

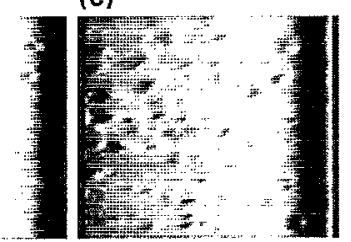

(f)

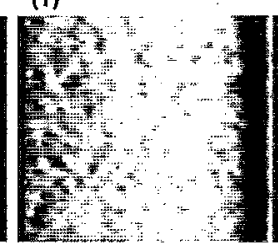

$\mathrm{K} \underset{300 \mathrm{~nm}}{\longrightarrow}$
FIG. 4. Sequentially obtained wide scan ( $500 \mathrm{~nm} \times 500 \mathrm{~nm})$ AFM top view images of $n$-InSe. Time after the start of the measurement: (a) $0 \mathrm{~s}$, (b) $40 \mathrm{~s}$, (c) $80 \mathrm{~s}$, (d) $120 \mathrm{~s}$, (c) $160 \mathrm{~s}$, (f) $200 \mathrm{~s}$.

gram of the flatness of this image [Fig. 5(a)] shows that the mean flatness is $0.05 \mathrm{~nm}$ and confirms the very flat surface. As the scan was repeated, the valley and hill appeared in the image and the flatness decreased as Figs. 4(b) -4 (f) show. There are hardly any flat parts left in Fig. 4(f). The histogram of this image [Fig. 5(b)] shows that the mean flatness of the surface is $\sim 0.4 \mathrm{~nm}$. One must, however, note that the absolute value of the flatness may not be reliable because of the aforementioned reasons. Thus, one can conclude that the AFM imaging itself damages the surface. In all the valley/hill structures, the lefthand side is lower than the right-hand side, i.e., the lefthand side is the valley and the right-hand side the hill. It seems that these observed structures reflect the direction of tip movement. The tip was scanned from right to left.

The effect of imaging is more clearly seen in Fig. 6 which is a $500 \mathrm{~nm} \times 500 \mathrm{~nm}$ line scan image of InSe after the small size ( $50 \mathrm{~nm} \times 50 \mathrm{~nm}$ ) imaging. In this case scanning was carried out relatively slowly (4.3 lines/s $\times 200$ lines/image). It is clear that a mound was created at the spot where the AFM measurement had been conducted. This result suggests that the bonding between the van der Waals layers was loosened and the distance between the (a)

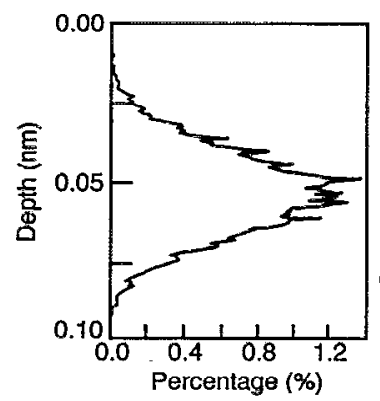

(b)

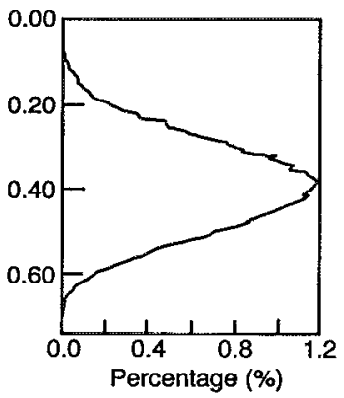

FIG. 5. The histogram of the flatness of $500 \mathrm{~nm} \times 500 \mathrm{~nm}$ region of $n$-InSe (a) for Figs. $4(a)$ and $4(b)$ for Fig. $4(f)$.

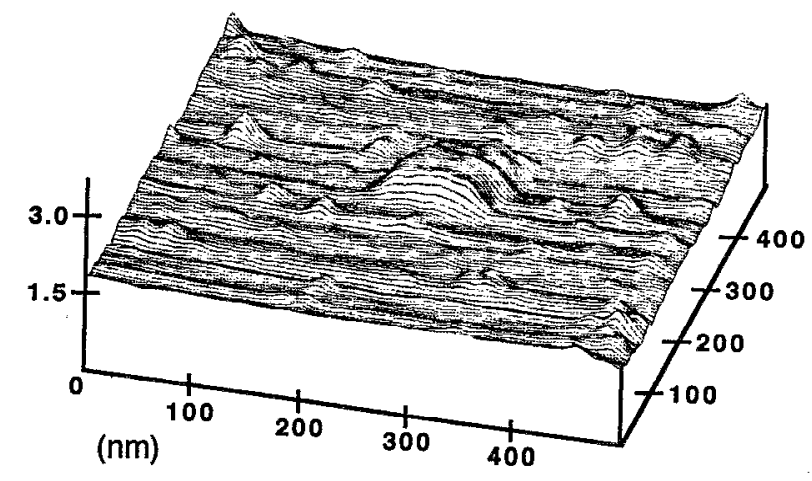

FIG. 6. Wide scan AFM line scan image ( $500 \mathrm{~nm} \times 500 \mathrm{~nm}$ ) of $n$-InSe after small scan $(50 \mathrm{~nm} \times 50 \mathrm{~nm}$ ) imaging for $2.5 \mathrm{~min}$.

layers increased as a result of the scan of the tip during AFM imaging. The mound observed in Fig. 6 was imaged as a hill and valley structure similar to the one observed in Fig. 5 if the image was obtained with a faster scan rate (19.5 lines/s $\times 200$ lines/image) which was used for obtaining the images shown in Fig. 5. Thus, this hill/valley structure seems to contain the artifact caused by the insufficient feedback control. When the tip started to feel the mound, the piezo scanner on which the sample was placed started to shrink as a result of feedback control and the trace of the image started to go up. When the tip reaches the top of the mound, the shrink level of the scanner should stay constant. However, if the feedback control cannot follow, the scanner shrinks further, i.e., the mound looks higher than it actually is, and then the scanner expands because of the feedback control, i.e., the image gives a valley. Since the tip was scanned from right to left, the mound was imaged as a hill on the right-hand side and a valley on the left.

It is expected that stable images may be obtained by imaging with less force. Unfortunately, however, it is very difficult to conduct out imaging with a lower force in air possibly due to the existence of the meniscus force. AFM imaging with less force is thought to be possible in liquids. ${ }^{22}$ Actually, we were able to obtain atomically resolved AFM images of InSe in water and in electrolyte solution with less force $(\sim 1 \mathrm{nN})$ and images were more stable in these media. ${ }^{23}$

The tip-induced damage reported here should not only be considered as a negative effect, because it opens up the possibility of nanofabrication of the surface with the AFM tip.

\section{ACKNOWLEDGMENTS}

Thanks are due to Dr. Chevy, Universite Pierre et Marie Curie-Paris VI for providing us with the InSe crystals. This work was partially supported by a Grant-in-Aid for Scientific Research (04555191) of the Ministry of Education, Science, and Culture and the Iketani Foundation for Science and Technology.

${ }^{\prime}$ R. M. A. Lieth, Ed., Physics and Chemistry of Materials with Layered Structures (Reidel, Dordarent-Holland, 1977), Vol. 1, p. 225. 
${ }^{2}$ V. N. Katerinchuk, Z. D. Kovalyuk, and I. V. Mintyanskii, Sov. Phys. Solid State 25, 94 (1983).

${ }^{3}$ S. M. Atakishiev and G. A. Aknundov, Phys. Status Solidi 32, K33 (1969).

${ }^{4}$ H. J. Lewerenz, H. Gerischer, and M. Lubke, J. Electrochem. Soc. 131, 100 (1984).

${ }^{5}$ A. Segura, A. Chevy, J. P. Guesdon, and J. M. Besson, Solar Energy Mater. 2, 159 (1979/1980).

${ }^{6}$ R. W. Damon and R. W. Redington, Phys. Rev. 96, 1498 (1954).

${ }^{7}$ J. C. Merle, R. Bartiromo, E. Borsella, M. Piacentini, and A. Savoia, Solid State Commun. 28, 251 (1978).

${ }^{8}$ A. Segura, J. P. Guesdon, J. M. Besson, and A. Chevy, J. Appl. Phys. 54, 876 (1983).

${ }^{9}$ G. Amato, C. Manfredotti, M. Meliga, and W. Mellano, Solar Cells 13, 19 (1984).

${ }^{10}$ T. Tenne, B. Theys, J. Rioux, and C. L.-Clement, J. Appl. Phys. 57, 141 (1985).

"C. Levy-Clement, N. L. Nagard, O. Gorochov, and A. Chevy, J. Elcctrochem. Soc. 131, 790 (1984).

${ }^{12}$ P. Carlsson, B. Holmström, K. Uosaki, and H. Kita, Appl. Phys. Lett. 53, 965 (1988).
${ }^{13}$ S. Eriksson, P. Carlsson, B. Holmström, and K. Uosaki, J. Appl. Phys. 69, 2324 (1991).

${ }^{14}$ K. Uosaki, S. Kaneko, H. Kita, and A. Chevy, Bull. Chem. Soc. Jpn. 59, 559 (1986).

${ }^{15}$ T. R. Albrecht and C. F. Quate, J. Vac. Sci. Technol. A. 6, 371 (1988).

${ }^{16} \mathrm{M}$. Weimer, J. Kramer, C. Bai, J. D. Baldeschwieler, and W. J. Kaiser, J. Vac. Sci. Technol. A 6, 336 (1988).

${ }^{17}$ H. Fuchs, R. Laschinski, and T. Schimmel, Europhys. Lett. 13, 307 (1990).

${ }^{18}$ A. Chevy, A. Kuhn, and M. S. Martin, J. Cryst. Growth 38, 118 (1977).

${ }^{19}$ B. Celustka and S. Popovic, J. Phys. Chem. Solids 35, 287 (1974).

${ }^{20}$ A. Likforman and M. Guittard, Compt. Rend. (Paris) C279, 33 (1974).

${ }^{21}$ A. Likforman, D. Carre, J. Etienne, and B. Bachet, Acta Cryst. B 31, 1252 (1975).

${ }^{22}$ A. L. Weisenhorn, P. Maivald, H.-J. Butt, and P. K. Hansma, Phys. Rev. B 45, 11226 (1992).

${ }^{23} \mathrm{~K}$. Uosaki and M. Koinuma, J. Electroanal. Chem. (in press). 
Journal of Applied Physics is copyrighted by the American Institute of Physics (AIP). Redistribution of journal material is subject to the AIP online journal license and/or AIP copyright. For more information, see http://ojps.aip.org/japo/japcr/jsp

Copyright of Journal of Applied Physics is the property of American Institute of Physics and its content may not be copied or emailed to multiple sites or posted to a listserv without the copyright holder's express written permission. However, users may print, download, or email articles for individual use. 